\title{
Investigation of the effect of spur dike length on the scour depth near the spur dike at the 90 degree position and the 180 degree bend of the rivers
}

\author{
Reza M omenzadeh ${ }^{1}$, Armin makvandi ${ }^{2}$, Roozbeh Aghamajidi ${ }^{3}$ \\ ${ }^{1}$ Msc of civil Engineering, Islamic Azad University, Sepidan branches \\ ${ }^{2}$ Msc of civil Engineering, Islamic Azad University, sepidan branch, \\ email: makvandi_armin@yahoo.com \\ ${ }^{3}$ Assistant Professor of Civil Engineering, Islamic Azad University, Sepidan Branch, \\ Roozbeh1381@yahoo.com
}

\begin{abstract}
One of the most common ways of organizing and controlling the side erosion in the bend of rivers is the use of spur dike. The spur dike prevents the strong flow of water along the coast by directing the flow towards the river, preventing the erosion of the river coast. Moreover, the new pattern of flow causes scouring around the spur dike. One of the parameters affecting the scouring in the entrance of spur dikes is the effect of spur dike length. In order to investigate the effect of spur dike length in the bend on the scouring process, experiments were carried out in a laboratory flume with 180 degree bend with $R / B=4.7$ made of Plexiglas. In this research, by placing the spur dike in a laboratory flume in a 90 degree position with lengths of 8,10 and $12 \mathrm{~cm}$ and with discharge of $28 \mathrm{l} / \mathrm{s}$ and a fixed depth of $13 \mathrm{~cm}$, the phenomenon of scouring around the spur dike in a clear water state was investigated.For flume-floor materials, natural sand with uniform granulation with $D 50=2 \mathrm{~mm}$ and uniformity coefficient of 1.7 was used. The results of this study show that as the length of the spur dike increases, the depth of scouring around it would also increase. In addition, with increasing flow discharge and positioning of the spur dike in the bend, the dimensions of the hole and the length of stack at the spur dike downstream also increase.
\end{abstract}

Keywords: spur dike, scouring, river bend, spur dike length.

\section{Introduction}

Spur dikes are structures used to organize the river in a bend or direct route. One of the main problems in the river bends is the formation of secondary flows and the erosion of the outer wall of the bend, which can prevent the erosion with the construction of a spur dike in the outer bend. These structures extend from the coast to the main flow and cause local narrowing inside the flow. These structures are constructed sometimes individually and sometimes in sequence and cause deviation of flow from the sides and prevent its collision with the coastal wall. In addition, they cause sediments deposit in vicinity of the main coast by creating rotatory flows in the downstream. This gradually develops and stabilizes the river wall. One of the most important issues related to the construction of spur dikes is scouring around the spur dike. By studying the important parameters of spur dike, its impact on the maximum depth of scouring and coastal protection can be evaluated. Many studies have been conducted with regard to scouring around a spur dike in the direct route and there are many relations to calculate the scouring depth around the spur dike. Some of the studies conducted on the direct route of the river include Miri (1999), Nasrollahi (2001), Garde et al. (1961), Gill (1972), Rogernam and Wachuko (1983), Ghodsian and Tehrani (2001). The complexity of the conditions of the flow pattern in the bend associated with the complexity of the flow around the spur dike complicates the flow pattern around the spur dike in the bend. Little research has been conducted on the spur dike in the bend. Some of them include Mesbahi (1992), Perdovsky et al (1995), Soleyman et al. (1997), Jiri and Shimuzu (2004). Despite the significant use of the spur dike in the river's bend, there is still no reference to design and determine the depth of scouring in the river bend. Therefore, the necessity of using a laboratory model to investigate the flow behavior is inevitable. In this research, the relationship between the length of the spur dike and the dimensions of the scouring hole was determined by installing a single spur dike with different lengths at 90 degree position in a laboratory flume with a 180 degree bend and the substrate topography at different discharges. 


\section{Materials and methods}

According to studies, the scouring phenomenon around a spur dike is affected by five main factors of channel geometry, spur dike characteristics, sediment characteristics, flow characteristics and fluid properties. In this research, parameters of the channel geometry, the length of the spur dike, the depth of flow, the properties of the bed materials and the properties of the fluid were constant, and the parameters of the positioning angle in the bend and flow discharge during the experiments were variable. Given what was stated above, the following relation was used to study the effects of variables affecting the equilibrium scouring around a spur dike in bend:

$$
\frac{d z_{m a z}}{L}=f(\theta, Q)
$$

Where,

$=\theta=$ the angle of spur dike positioning in bend

$=Q=$ flow discharge

$=d z_{\text {maz }}=$ depth of maximum spur dike in equilibrium state

$\mathrm{L}=$ spur dike length

The experiments were carried out in an arc-shaped flume with a central angle of 180 degree, center radius of $\mathrm{R}=2 . \mathrm{m}$ and width of $\mathrm{B}=0.6 \mathrm{~m}$. The relative curvature of the bend was $\mathrm{R} / \mathrm{B}=4.7$, placing the bend in the soft bend category. The inlet direct channel is connected to a channel with bend of 180 degree. This bend -shaped channel is connected to flow depth control valve and outlet tank by another direct channel with length of $5.5 \mathrm{~m}$ (Figure $1)$.

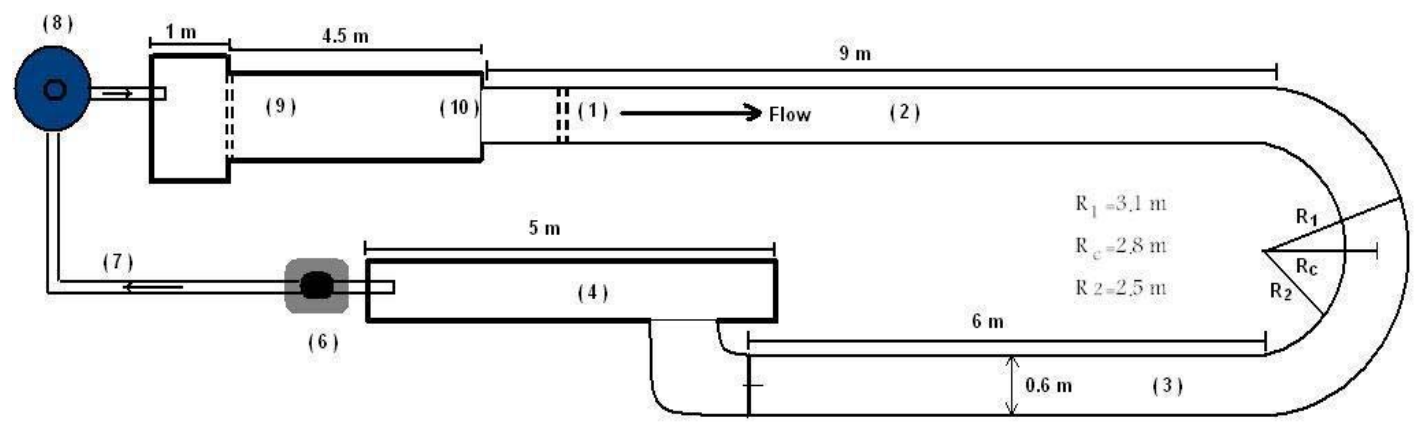

(5)

Figure 1 characteristics of flume bend

According to Donut's recommendation [7], the maximum spur dike length should be considered between 10 to $20 \%$ of the channel width. Therefore, in order to model the size of the spur dike, a wooden plate with thickness of $3 \mathrm{~mm}$ with lengths o 8,10 and $12 \mathrm{~cm}$ with an obstruction percentage of $13.33 \%, 16.66 \%$ and $20 \%$ of the width of the flume, respectively, was selected. Eliotto and Hager [8] recommended water depths of more than $20 \mathrm{~mm}$ in order to prevent the roughness effects. In all the tests, the water depth was considered constant and 13 $\mathrm{cm}$. As local scouring was investigated in clear water conditions, in order to prevent erosion and sediment transport in the upstream of the spur dike, the average flow rate should be less than the critical speed $\left(u<u_{c}\right)$. In order to investigate the effect of length and discharge on the scouring, discharges of 20, 24 and $281 / \mathrm{s}$ were considered for testing on spur dike at position of 90 degree. It was measured by a 60 degree triangular overflow at the beginning of the flume inlet. To obtain the equilibrium time, a long-term test was carried out for 10 hours at a maximum discharge of $28 \mathrm{l} / \mathrm{s}$ for a position of 90 degree bend and spur dike length of $12 \mathrm{~cm}$. During the experiment, the scouring depth was measured by a depth meter with precision of $1 \mathrm{~mm}$. The time interval between the measurements up to first 60 minutes, due to rapid erosion, was considered 10 minutes, and then 20 minutes, and finally 30 minutes. Diagram 3 shows the equilibrium time for discharge of $28 \mathrm{l} / \mathrm{s}$ in a position of 90 degree. Given the granulation of floor sediments, it is seen that $86 \%$ of the final scouring occurs in the first 120 minutes. As this study compares the rates of scouring in the entrance of the spur dike in different lengths, the 2hour time was considered for all experiments. 


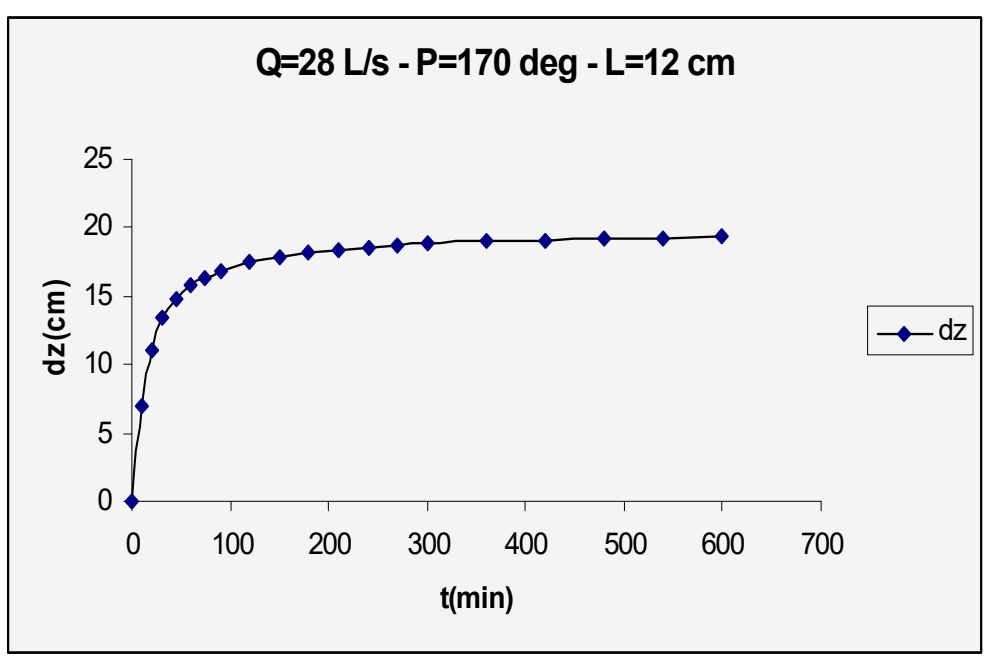

Figure 2: the diagram of equilibrium time for a $12-\mathrm{cm}$ spur dike at position of 90 -degree bend and with discharge of $281 / \mathrm{s}$.

To perform experiments, the spur dike was first installed at the desired position. Then, the floor sediments were extended uniformly in the longitudinal and transverse directions of the flume. Before launching the pump, the end valve was closed, and then, the clear water was slowly directed to the channel. After rising water and ensuring that the sediment has got wet after a few hours, the pump was slightly launched, and the discharge was brought to the considered rate slowly by the main gate valve on the inlet pipe. By precise adjustment of the downstream valve, the depth of $13 \mathrm{~cm}$ and a desired discharge were obtained. After two hours of equilibrium time, the pump was turned off and the water in the channel was drained slowly to prevent any effect on the topography of the substrate. After several hours and full discharge of water from channel, the topography of the substrate was taken around the cylindrical base at different positions and discharges by depth meter with precision of $100 \mathrm{~mm}$. In order to accurately evaluate the changes in the substrate along the transverse distance, the time interval of $2 \mathrm{~cm}$ was considered, and in the longitudinal position, it was also considered $2 \mathrm{~cm}$.

Results In all experiments, after adjusting the discharge and flow depth, vortices were immediately formed around the spur dike and scouring began at a very high speed. With the formation of the scour cavity, sediments were transported from the cavity to the lower side. After the start of the experiment, the sediments of the scour cavity reach to a zone, where the effect of the spur dike on that zone has decreased. In this situation, sediments of scour cavity are transported to the opposite wall. In the same zone, depending on the hydraulic conditions of the flow, sedimentation is caused by minimal scouring in the outer wall of the bend (Figure 3). Due to the deviation of the flow through spur dike, a dip is formed in the vicinity of the spur dike, which this dip was observed in all experiments. However, its dimensions were different for different positions of spur dike installation. In the vicinity of the spur dike entrance and in high discharges, this dip sometimes collides with outer wall and leads to scouring in the bend wall, and sometimes this collision does not occur and scouring is not created and sedimentations occur. It is clear that the parameters affecting the dimensions of this dip are the length of scouring and the flow discharge.
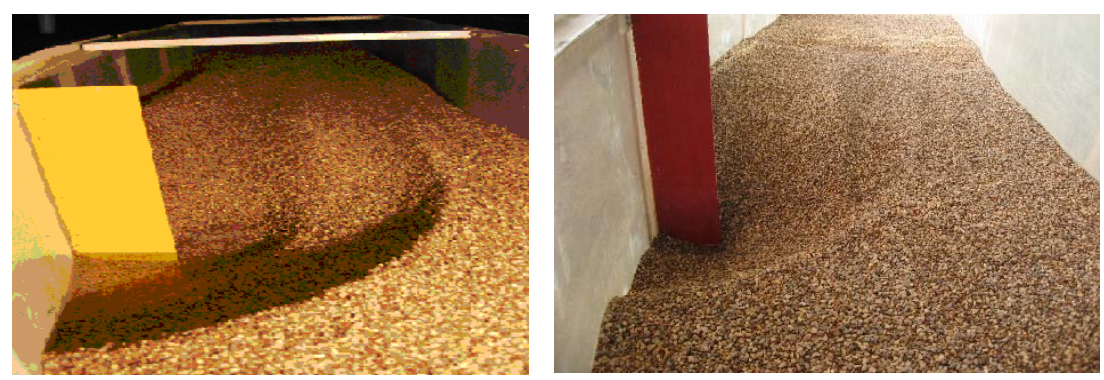

Figure 3. Dipping and sedimentation upstream and downstream of spur dike with length of 8 and $10 \mathrm{~cm}$ and 90 degree position

Investigating the effect of spur dike length on its surrounding scouring

Given the position of spur dike in the river width, the cross section of the river is reduced in this part for passing of flow. Therefore, it can be expected that increasing the length of the spur dike to cause an increase in the percentage of blockage, and the scouring in its entrance will increase with increasing its length. Its reason is analyzed below. Due to the increase in the length of the spur dike, followed by increased blockage, and due to the constant depth of the flow in the entrance, the velocity and thus the Froude number of increase, leading to increased shear stress on the floor materials and increased scouring. 

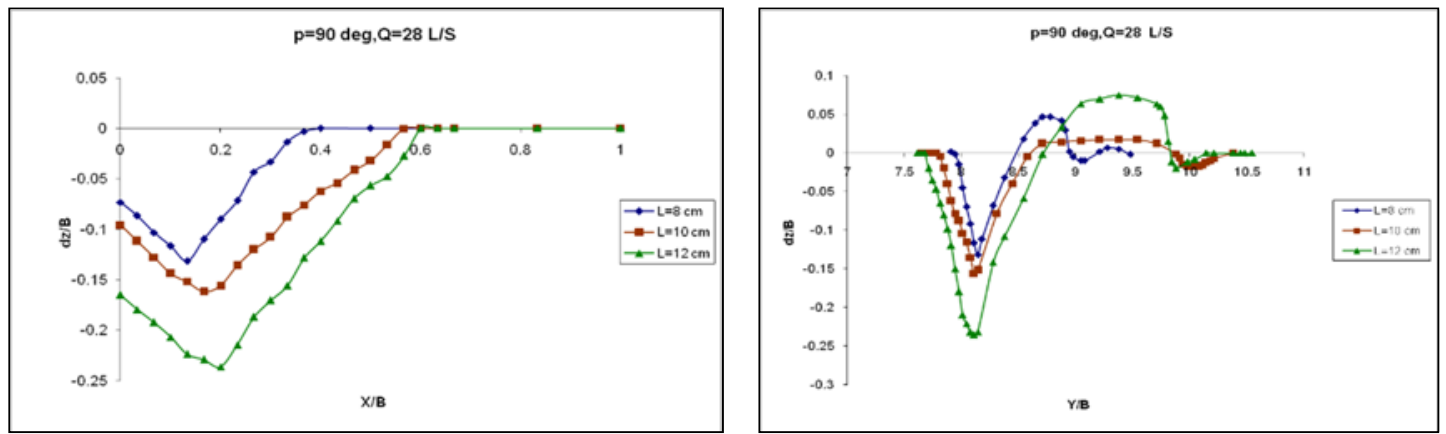

Figure 4. Transverse and longitudinal profiles of maximum depth of scouring with different lengths in a discharge of $28 \mathrm{l} / \mathrm{s}$
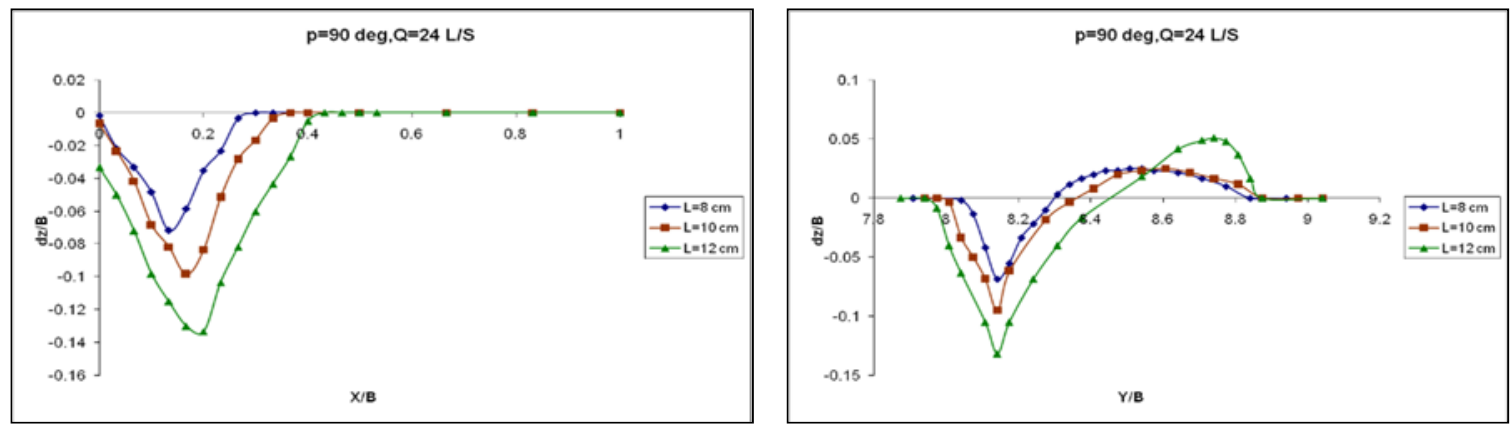

Figure 5. Transverse and longitudinal profiles of maximum depth of scouring with different lengths in a discharge of 24 1/s
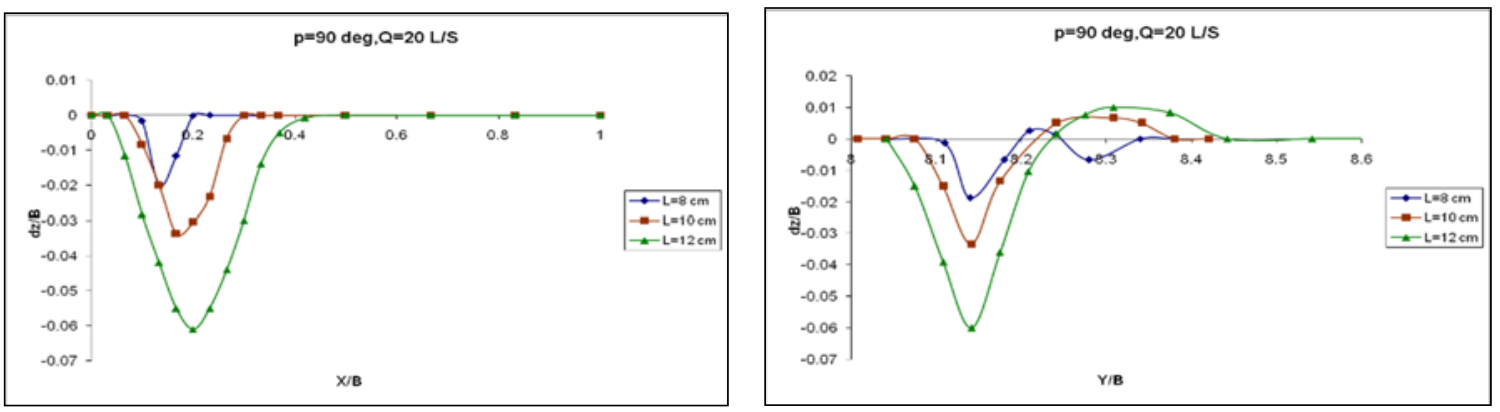

Figure 6. Transverse and longitudinal profiles of maximum depth of scouring with different lengths in a discharge of $201 / \mathrm{s}$

Changes in scour depth relative to flow discharge in bend

As the flow depth and channel width are constant, with increasing discharge, the flow velocity increases, leading to increased shear stress (which is the main factor for the start of motion of the particles) and with increasing stress, the strength of the vortical flows in the entrance of the spur dike (Which is the cause of eroding hole in entrance of spur dike) increases, leading to deepening of scouring and the wider dimensions of the eroding wall.
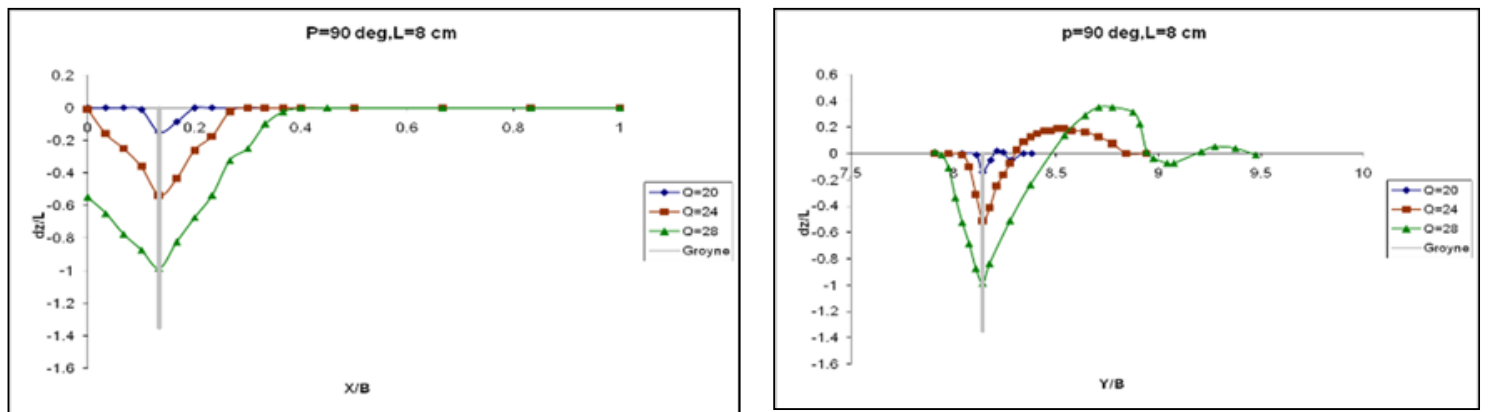

Figure 7. Transverse and longitudinal profiles of maximum scour with length of $8 \mathrm{~cm}$ in different discharges 

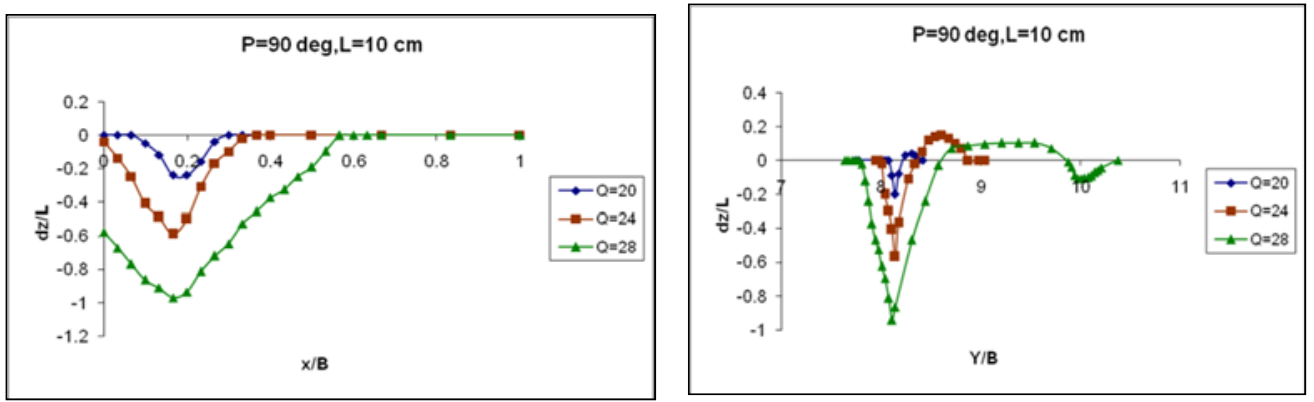

Figure 8. Transverse and longitudinal profiles of maximum scour with length of $10 \mathrm{~cm}$ in different discharges
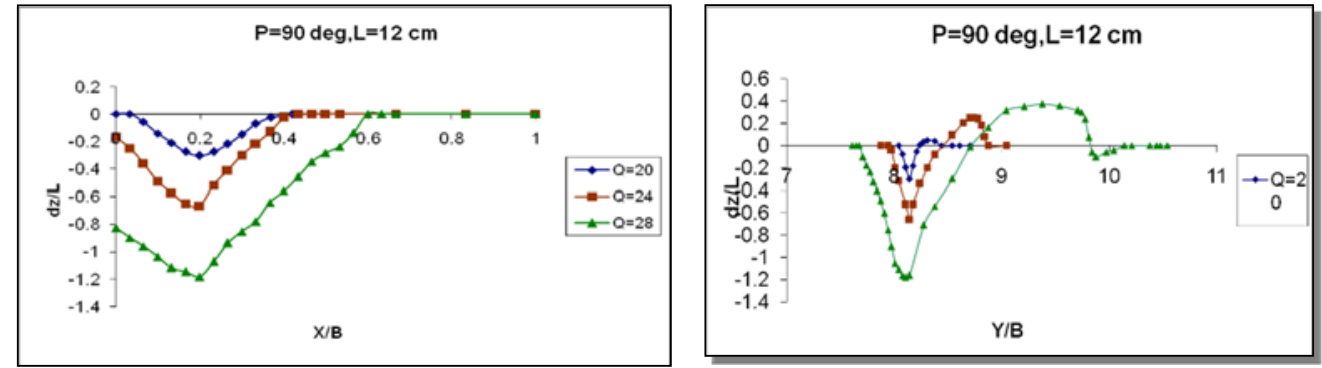

Figure 9. Transverse and longitudinal profiles of maximum scour with length of $12 \mathrm{~cm}$ in different discharges

\section{Discussion and conclusion}

Given the experiments and objective observations in experiments and the curves examined, the following results are obtained:

The effect of spur dike length on the depth of eroding hole

1-discharge of $201 / \mathrm{s}$

- By $25 \%$ increase in the spur dike length (from $8 \mathrm{~cm}$ to $10 \mathrm{~cm}$ ), the rate of scouring at its entrance increased by $23.22 \%$. In other words, by 1.25 times of increase in spur dike length, the scouring at its entrance increases by 2.23 times.

- $20 \%$ increase in the spur dike length (from $10 \mathrm{~cm}$ to $12 \mathrm{~cm}$ ), the rate of scouring at its entrance increased by $43.98 \%$. In other words, by 1.2 times of increase in spur dike length, the scouring at its entrance increases by 1.43 times.

- By $50 \%$ increase in the spur dike length (from $8 \mathrm{~cm}$ to $12 \mathrm{~cm}$ ), the rate of scouring at its entrance increased by $221.42 \%$. In other words, by 1.5 times of increase in spur dike length, the scouring at its entrance increases by 3.21 times.

2-discharge of $241 / \mathrm{s}$

- By $25 \%$ increase in the spur dike length (from $8 \mathrm{~cm}$ to $10 \mathrm{~cm}$ ), the rate of scouring at its entrance increased by $73.52 \%$. In other words, by 1.25 times of increase in spur dike length, the scouring at its entrance increases by 1.73 times.

- By $20 \%$ increase in the spur dike length (from $10 \mathrm{~cm}$ to $12 \mathrm{~cm}$ ), the rate of scouring at its entrance increased by $11.52 \%$. In other words, by 1.2 times of increase in spur dike length, the scouring at its entrance increases by 1.11 times.

- By $50 \%$ increase in the spur dike length (from $8 \mathrm{~cm}$ to $12 \mathrm{~cm}$ ), the rate of scouring at its entrance increased by $93.52 \%$. In other words, by 1.5 times of increase in spur dike length, the scouring at its entrance increases by 1.93 times.

\section{2-discharge of $28 \mathrm{l} / \mathrm{s}$}

- By $25 \%$ increase in the spur dike length (from $8 \mathrm{~cm}$ to $10 \mathrm{~cm}$ ), the rate of scouring at its entrance increased by $15.29 \%$. In other words, by 1.25 times of increase in spur dike length, the scouring at its entrance increases by 1.15 times.

- By $20 \%$ increase in the spur dike length (from $10 \mathrm{~cm}$ to $12 \mathrm{~cm}$ ), the rate of scouring at its entrance increased by $20.40 \%$. In other words, by 1.2 times of increase in spur dike length, the scouring at its entrance increases by 1.20 times.

- By $50 \%$ increase in the spur dike length (from $8 \mathrm{~cm}$ to $12 \mathrm{~cm}$ ), the rate of scouring at its entrance increased by $38.82 \%$. In other words, by 1.5 times of increase in spur dike length, the scouring at its entrance increases by 1.38 times. 
- The effect of flow discharge on depth of eroding hole

8 cm spur dike

- By $20 \%$ increase in rate of flow discharge (from 20 to 24 ), the rate of scouring increases by $264 \%$. In other words, 1.2 times of increase in the flow discharge increases the rate of scouring by 3.64 times.

- By $16.66 \%$ increase in rate of flow discharge (from 24 to 28 ), the rate of scouring increases by $150 \%$. In other words, 1.16 times of increase in the flow discharge increases the rate of scouring by 2.5 times.

- By $40 \%$ increase in rate of flow discharge (from 20 to 28 ), the rate of scouring increases by $810.69 \%$. In other words, 1.4 times of increase in the flow discharge increases the rate of scouring by 9.10 times.

$10 \mathrm{~cm}$ spur dike

- By $20 \%$ increase in rate of flow discharge (from 20 to 24 ), the rate of scouring increases by $183 \%$. In other words, 1.2 times of increase in the flow discharge increases the rate of scouring by 2.83 times.

- By $16.66 \%$ increase in rate of flow discharge (from 24 to 28 ), the rate of scouring increases by $66.10 \%$. In other words, 1.16 times of increase in the flow discharge increases the rate of scouring by 1.66 times.

- By $40 \%$ increase in rate of flow discharge (from 20 to 28 ), the rate of scouring increases by $370 \%$. In other words, 1.4 times of increase in the flow discharge increases the rate of scouring by 4.70 times.

$12 \mathrm{~cm}$ spur dike

- By $20 \%$ increase in rate of flow discharge (from 20 to 24), the rate of scouring increases by $120 \%$. In other words, 1.2 times of increase in the flow discharge increases the rate of scouring by 2.20 times.

- By $16.66 \%$ increase in rate of flow discharge (from 24 to 28 ), the rate of scouring increases by $4.33 \%$. In other words, 1.16 times of increase in the flow discharge increases the rate of scouring by 1.79 times.

\section{References}

[1] Ahmed,M.,(1953),"Experiments on Design and Behavior of Spur dikes",Proc. Of Cong .of IAHR, p.145

[2] Garde, R.J.,et al, (1961),"Study of Scour Around Spur-dikes", Journal ofHydraulic Division.,

[3] Gill,M.A,(1972),"Erosion of Sand Beds Around Spur dikes", Journal of Hydraulic Division.,

[4] Lacey ,r.w., Millar ,j. and Androbert, G., (2014),"Reach scale hydraulic assessment of instream salmonid habitat restoration",Journal of the American water resources association vol.40,1631-1644

[5] Petersen, M .S.,(1986),"River engineering",Prentice-Hall, Englewood Cliffs ,N.J.,330P.

[6] Donat, M .,(1995),"Bionengineering techniques for streambanj restoration: A review of Central European practices", Watershed restoration project report No. 2, University of British Colombia,Austria.

[7] Oliveto, G. and Hager, W.H., (2002) “Temporal Evolution of Clear-Water Pier and Abutment Scour", Journal of Hydraulic Engineering, ASCE, Vol.128 (9), pp. 811-820. 